\title{
A Decision Support System to Determine the Ideal Number of Workers Using a Line Balancing Method
}

\author{
Hazel A. Caparas \\ Department of Industrial Engineering, Bulacan State University, \\ City of Malolos, Bulacan \\ E-mail: hazel.caparas@yahoo.com
}

Received 26 December 2016; Accepted 22 July 2017;

Publication 4 August 2017

\begin{abstract}
This paper presents an analysis of a typical assembly line problem which examines how to balance a manual packing line of a local company engaged in manufacturing snack foods. The subject assembly line consists of various manual activities thus seeing the need to set up standard time in order to control excess labor cost and to avoid forcing the worker to perform beyond his or her normal capacity. The work aims to initially establish time standards for activities involved in every workstation through time study. The appropriate time study technique for the subject process line will be briefly discussed on the study. As a result, line balancing approach will be utilized to determine the optimal number of manpower requirement per workstation. Given this method, the study seeks to eliminate build-up of work-in-process between activities, minimize the deviation of utilization of workstations, maximize the capacity of the line and minimize the labor-hour expended per unit of product. The desired outcome of the study is to develop a configuration that will serve as a decision support system for the person in charge to estimate the ideal number of crew to be positioned per workstation. Additionally, the benefits of
\end{abstract}

Journal of Industrial Engineering and Management Science, Vol. 1, 103-122.

doi: 10.13052/jiems2446-1822.2017.005

(c) 2017 River Publishers. All rights reserved. 
"walking-worker" will be introduced over a conventional fixed worker in an assembly line. The work will also provide the company an initial systematic procedure for setting up time standards and a performance control system for other product lines.

Keywords: Methods Engineering, Walking-worker, Decision Support System, Manual Packing, Motion and Time Study.

\section{Introduction}

One of fundamental resources of the production system is its manpower. Its integration into manufacturing processes is a significant element on converting various inputs into finished products. This factor is essential in order to operate the machines, assemble modules of a product, inspect the output the line, transfer and store finished goods. Seeing this account, utilization of manpower obviously has corresponding cost in creating the product. In general, firms classified labor cost into two categories which are costs incurred by direct labor and indirect labor. Labor cost that can be easily traced to the creation of individual unit of product is said to be as direct labor cost or touch labor since workers normally touch the materials as it moves from one process to another. Conversely, indirect labor costs are those labor costs that cannot be physically traced to the structure of products and can be accounted only at great cost and complexity. Through the company's objective of having a strong standing among its competitors, the firm has to develop a strategy and control to sustain and continuously expand its share in the market. The emergence of low-cost competition between brands necessitates most firms to reduce and control its manufacturing cost. Generally, it has been said that labor costs account for roughly $70 \%$ of firms' production costs (FRB Cleveland, 2006). As a result, increase in labor cost possibly will indicate raising the product price in order to recover rise in labor cost. Some basic approaches for controlling the labor cost of the product are reducing inputs while keeping output constant or increasing output while keeping inputs constant. Additionally, keeping track of the actual labor cost expended against the predetermined standards is also effective in controlling the cost of the product.

Taken as a whole, the study will seek to set up the optimum number of crew assigned on every work station for one of the assembly line of a local manufacturing firm engaged in producing variety of snacks. The study will make use of the general procedure of method and work measurement 
to establish time standards and to determine the best possible number of workers to be positioned on each activity on the assembly line. The major desired outcome will be establishing a fair, consistent and cost-effective time standards to be able to utilize workers at their normal pace without forgoing the efficiency of the line. As a result, there will be a control over the labor cost expended to create the product and consequently lead to decrease in cost of goods manufactured.

\subsection{Statement of Objectives}

The study aims to determine the ideal number of workers to be assigned on each workstation in order to decrease the amount of work-in-process between activities, reduce the deviation of utilization of workstations, maximize the capacity of the line and minimize the labor-hour expended per unit of product.

\subsection{Rationale of the Study}

The study has selected final packing of jelly products production line seeing that the entire process contains manual activities which required a definite time standards to be tracked. Establishing fair and consistent time standards for jelly products line through methods and work measurement is valuable both for employees and the company. Additionally, determining the ideal number of crew to be placed on each stages of the process would be a supplementary control over the actual labor cost of the product.

\subsection{Significance of the Study}

Setting-up time standards and determining the ideal number of manpower per workstation are highly beneficial due to the following potential advantages:

- Decrease in work-in-process between activities on the production line at the same time as increasing the throughput.

- Setting a minimum and fair time required in performing tasks in order to control labor cost per unit of product given the comfortable capacity of workers.

- Having defined basis for manpower requirement planning.

- Development of performance control system which comprises of setting time standards or goal, comparison of actual performance with the 
goal, tracking of performance, reporting variances larger than tolerable deviation and taking corrective action to eliminate causes of poor performance.

- Designing a systematic procedure in establishing time standards that may be applicable to other product lines of the company.

\subsection{Problem Statement}

Lack of time standards for activities involved in jelly products line results to the following inefficiency:

- Workers are required to perform beyond their acceptable rate.

- Workers may possibly work less than their normal pace.

- Unbalanced production line that resulted to build-up of work-in-process between activities.

These conditions are unproductive and inefficient. Given that there is an absence of exact basis for the number of workers lined-up for jelly products line, excess in labor cost per unit of the product is not controllable.

\subsection{Scope and Limitation of the Study}

The premise of the study involves setting of fair, consistent and cost-effective time standards for jelly products manual packing line through methods and work measurement, subsequently determining the ideal number of crew per workstations by means of line balancing. It will merely cover activities in producing brand 1 and 2 that are categorized as under direct labor or those positions that directly touch the product while being made. The study will be conducted in a local company engaged on manufacturing variety of snack foods.

\section{Analysis of the Present System}

\subsection{Manufacturing Process}

The study will focus particularly on final packing section since majority of the process is occupied with large number of manual activities that need to be measured. Produced jelly products are withdrawn from warehouse and take to manual packing to become finished products. The process is carried out with 


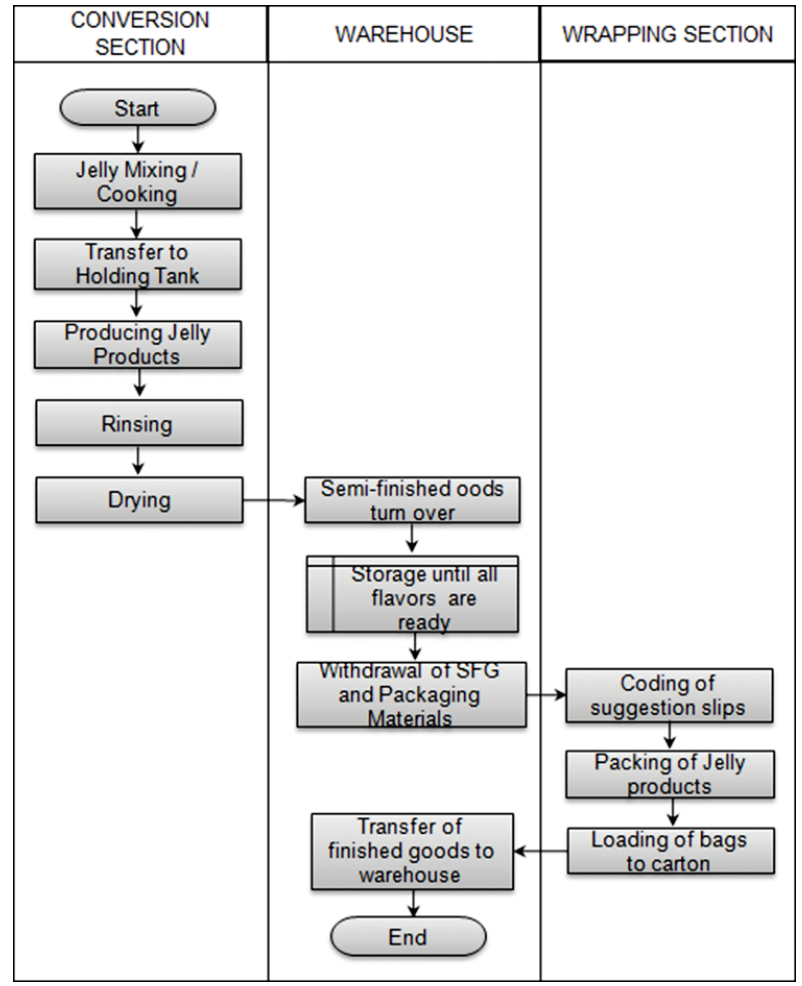

Figure 1 Jelly products process flow chart.

the aid of a conveyor and manual foot sealers. The wrapping section include stages such as withdrawal and distribution of jelly products and packaging materials from warehouse, counting and sorting of jelly products, loading of jelly products into preformed bags, coding of suggestion slips, loading of bags into carton, weighing of finished products and transferring finished goods to warehouse.

At present, the company measures its efficiency on using its manpower by means of determining actual labor-hour expended per unit of finished goods. The company follows a common practice of getting the workers total punched time on clock before and after the completion of the job. This scheme provides the duration of time to perform the entire operation without considering how much time are used up for personal, delay and fatigue allowances. 
Formula 1.0 - Measuring labor-hour per unit of product

Labor hour per case $=\frac{\text { Total punched time in completing the job (labor hour) }}{\text { Total output (cases) }}$

Actual labor-hour per case for the past production weeks are shown below.

Graph shows that actual labor-hour spent per unit of product for the past production weeks. The figure illustrates that data are unpredictable and inconsistent. Consequently, it indicates lack of control over required labor per unit of product. As displayed on the graphs, there are instances that workers are capable of producing as fast as 5.87 cases per hour of jelly products brand 1 and 2 . While there are cases that workers can produce output at the rate of as slow as 3.55 cases per hour. It is noticeable that there is a wide range between maximum and minimum rate of workers. These conditions are due to absence of systematic basis for allocating manpower on each workstation on the line. Also, the expected capacity of the line is not calculated methodically thus workers are not prompted if they are performing at diminishing rate.

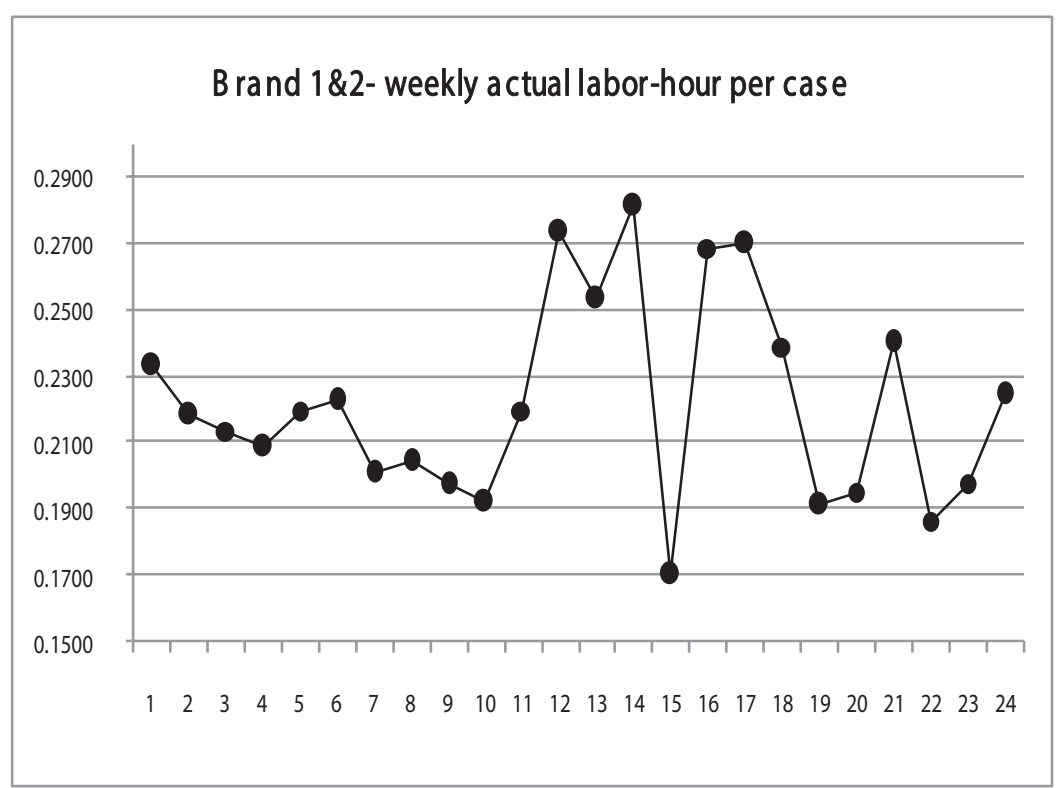

Figure 2 Labor-hour per case of Brand 1 and 2. 


\subsection{Present Flow Diagram}

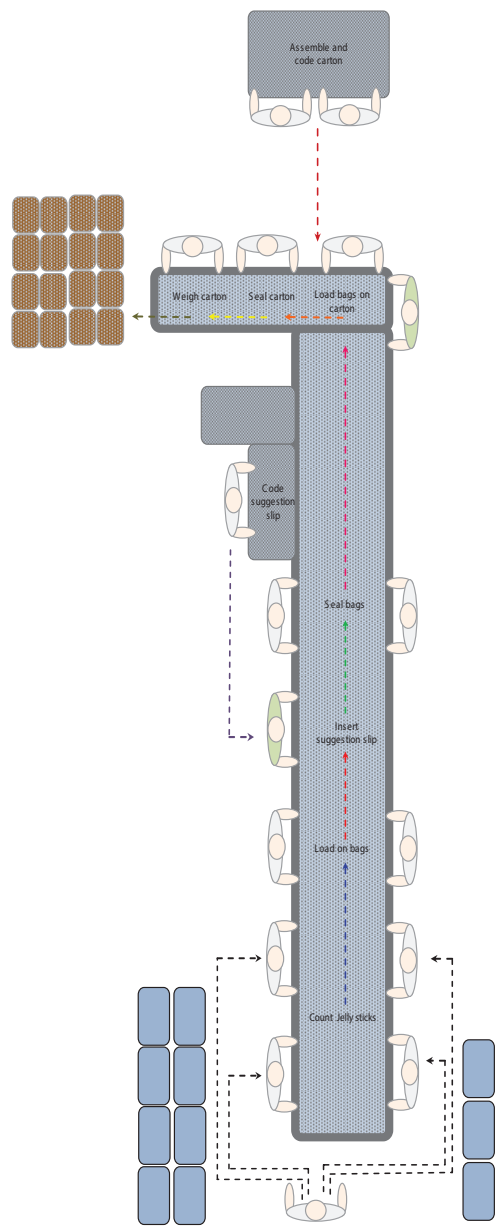

Figure 3 Present flow diagram of jelly products manual packing section.

Table 1 Existing manpower line-up for manual packing

\begin{tabular}{lc}
\hline Activity for Wrapping Section & Assigned Crew \\
\hline Semi-finished goods withdrawal & 3 \\
Packaging material withdrawal & 2 \\
Coding of suggestion slips & 1 \\
Packing of jelly products to bags & 11 \\
Loading of bags to carton & 3 \\
Total & 20 \\
\hline
\end{tabular}




\section{Methodology}

\subsection{Time Study}

There are some factors considered in choosing the worker to be time studied. It is essential to select the worker that performs the task at constant and normal pace. The worker should be doing the job for at least two weeks. In order to determine the number of observations to make, initial ten good readings are obtained from the line. The study makes use of snapback method seeing that each element are long enough for continuous method. Using a $95 \%$ confidence level and $\pm 5 \%$ precision, initial readings are subjected to the formula shown below to verify whether a sufficient number of observations have already taken. If a 95\% confidence level and a precision of $\pm 5 \%$ are considered, the formula will be:

Formula 2.0 - Observation sample size

$$
N^{\prime}=\left(\frac{\left(20 \sqrt{\left(N \sum x^{2}-\left(\sum X\right)^{2}\right)}\right)}{\sum X}\right)^{2}
$$

After determining the number of observations needed, more readings are taken until indicated sample size is obtained. Average observed time is computed for each job elements. Since the line includes short-cycle and repetitive work, only one rating is applied to adjust the time of the workers. An additional $10 \%$ overall allowance for each elements are given which consists of three 20-minute break-time or $8 \%$ personal allowance, $1 \%$ delay allowance and $1 \%$ fatigue allowance. The study follows the succeeding formula in getting the normal time and the standard time.

Formula 3.0 - Normal time

$$
\text { Normal Time }(N T)=\frac{\text { Observed time } x \text { Rating }}{100}
$$

Formula 4.0 - Standard time

$$
\text { Standard time }=N T x(1+\text { Allowance })
$$




\section{Results and Discussion}

\subsection{Time Standards}

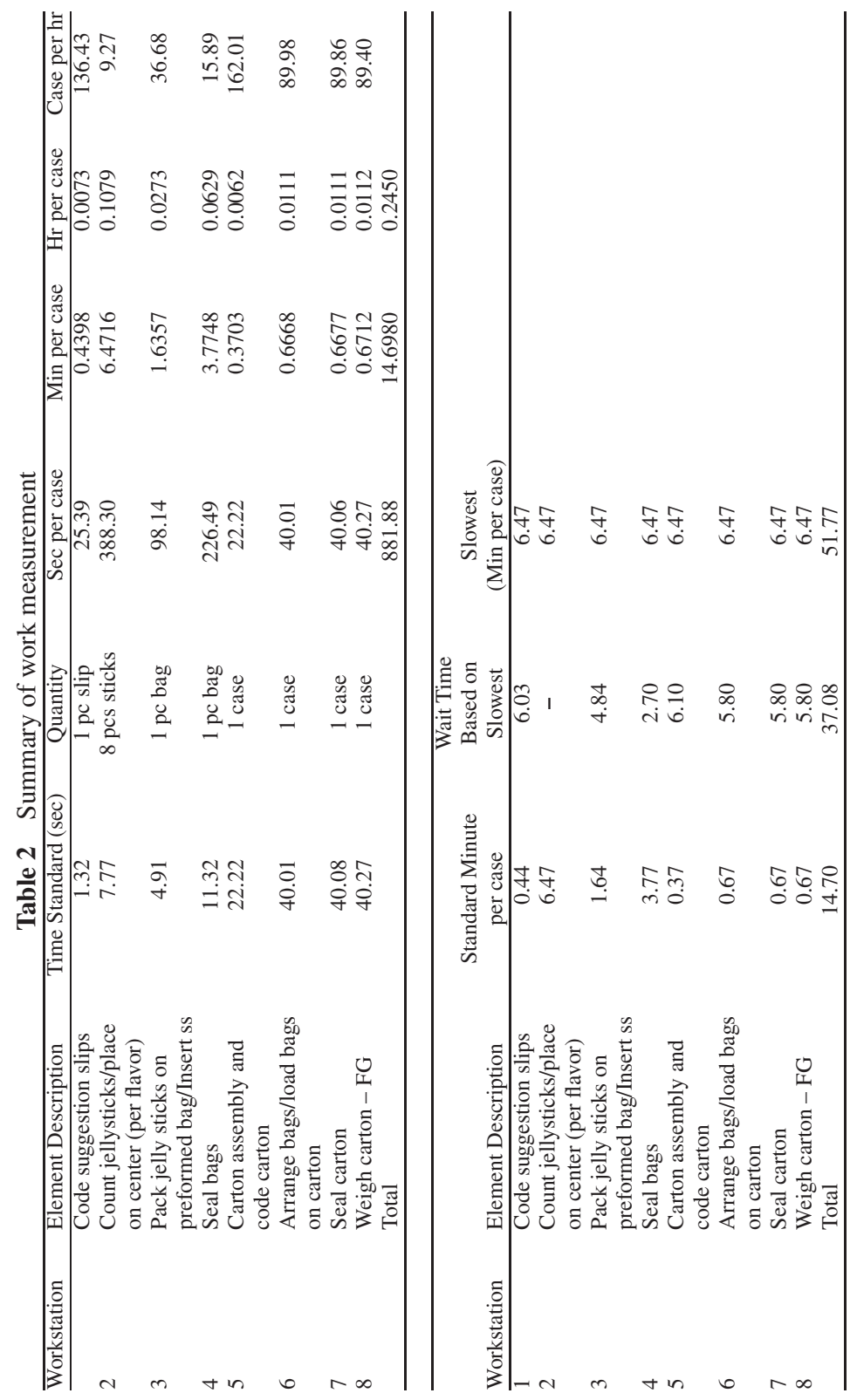


Formula 5.0 Efficiency and Idle \% of the line

$$
\begin{gathered}
\mathrm{E}=\frac{\sum \text { Standard time to perform opearation }}{\sum \text { Allowed Standard time }} \times 100 \\
\mathrm{E}=\frac{14.70}{51.77} \times 100 \\
\mathrm{E}=28.39 \% \\
\% \text { Idle }=71.61 \%
\end{gathered}
$$

\subsection{Line Balancing}

Basically, in order to balance the line, there are four criteria to be considered in this study.

- Zero build-up of work-in-process between activities. Each workstation is capable of processing the output of the preceding workstation consistently.

- Utilization $\%$ of the workstation must not exceed $85 \%$ of its available time so as not to be over utilized. Also, the study seeks to minimize the deviation of utilization \% among workstations.

- Manpower set-up with maximum output per unit of time.

- Minimum labor-hour expended per unit of product.

Given the actual data for the past 36 working days, it shows that the average output per shift is 380 cases. Thus, the succeeding manpower requirement and its configurations will assume to have an output of 380 cases per shift. Taking the current fixed-worker assembly line, ideal number per workstation has been computed based on average requirement of 380 cases per shift. Given an available time per shift of 660 minutes, it follows that allowable to complete one unit is 1.74 minutes.

Workstation 2 (Count jelly products/place on center per flavor) determines the output of the line.

Formula 6.0 - Output of the line

$$
\text { Capacity }=\frac{4 \text { workers } \times 60 \text { minutes }}{6.47 \text { standard minutes }}
$$

Capacity $=37.08$ cases per hour 


\subsection{Generation of Different Configurations of Manpower Set-up}

Configuration No. 1: Reorientation of the existing number of manpower set-up

Existing number of manpower line-up will still be used but there will be some changes on positioning crews in workstations. At present, there are 14 crews for the entire line. There will be an introduction of "walkingworker" in the line to balance the utilization of linked workstations. Activities such as coding of suggestion slips, packing of jelly products and inserting suggestion slips are clustered. Also, carton assembly, coding of carton and sealing of bags are grouped as single workstation. Excess one crew is situated on the position that dictates the output of the line. Configuration number 1 is summarized on the next tables.

$$
\begin{aligned}
& \text { Capacity }=\frac{5 \text { workers } \times 60 \text { minutes }}{6.47 \text { standard minutes }} \\
& \text { Capacity }=46.36 \text { cases per hour }
\end{aligned}
$$

Configuration No. 2: Combine workstations through linear "walking-worker" and determine the ideal number of crew needed per workstation.

In Configuration No. 2, there are four basic groups of activities or workstations. Clustered activities are formerly linked workstations that are capable of supporting other workstations that are fully utilized. In this configuration, it shows 12 crews is the optimum number of manpower to complete the average output per shift of 380 cases. Noticeably, there is build-up of work-in-process of 1.54 cases per hour at workstation 4 . It has been analyzed not to place additional crew in workstation 4 since it can be assisted by workstation 3 which is only $63.93 \%$ utilized. Configuration number 2 is summarized on the next tables.

$$
\begin{aligned}
& \text { Capacity }=\frac{5 \text { workers } \times 60 \text { minutes }}{6.47 \text { standard minutes }} \\
& \text { Capacity }=46.36 \text { cases per hour }
\end{aligned}
$$

Configuration No. 3: Using the sequence and clustering of activities in Configuration No. 2 develop manpower configurations if there are more than 380 cases production volume requirement.

The configuration is programmed in such a way that additional crew will be added if the initial computed number of manpower assigned in a 
114 H. A. Caparas

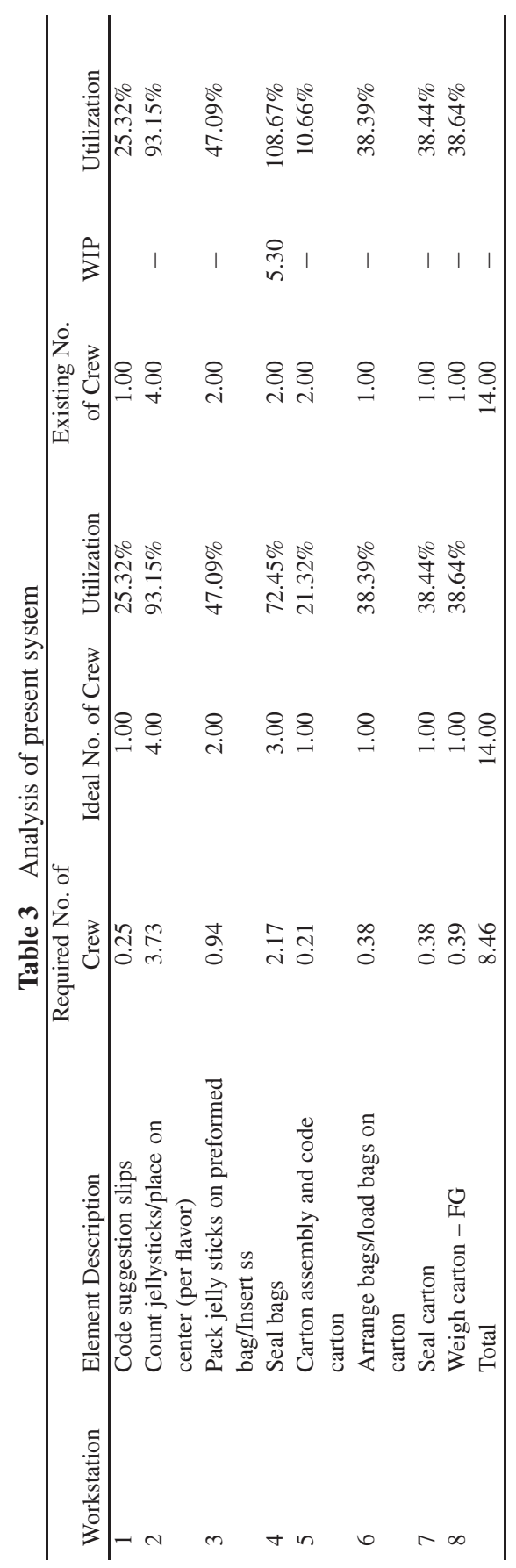




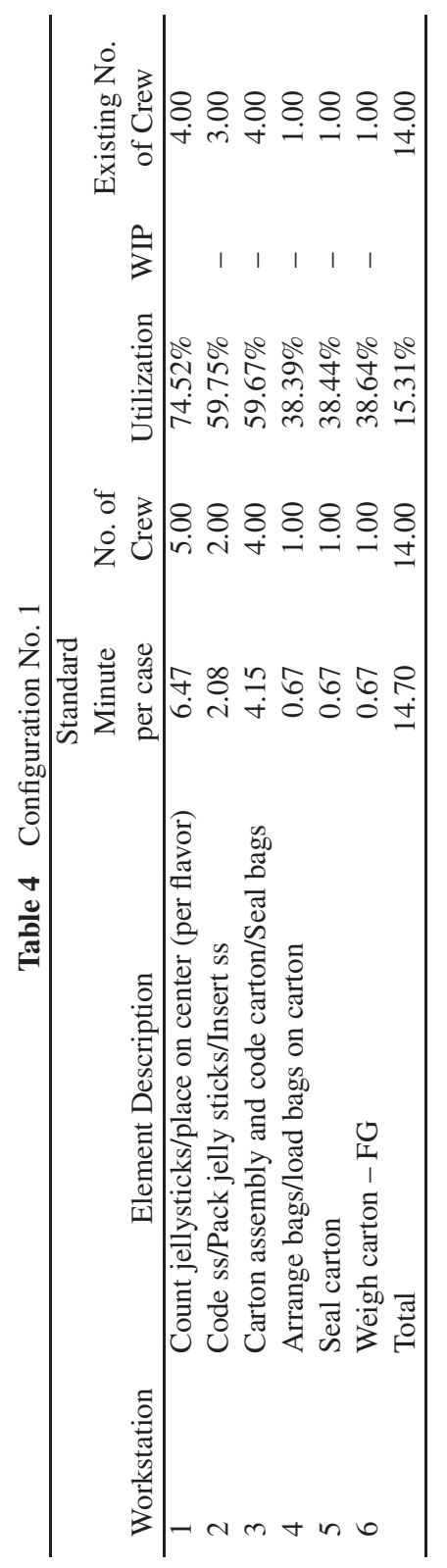




\section{H. A. Caparas}

workstation has beyond $85 \%$ utilization and if there are build-up of workin-process between activities. It is important to take full advantage of the number on manpower lined up by producing the maximum output the line can produce in order to minimize labor-hour expended per unit of product.
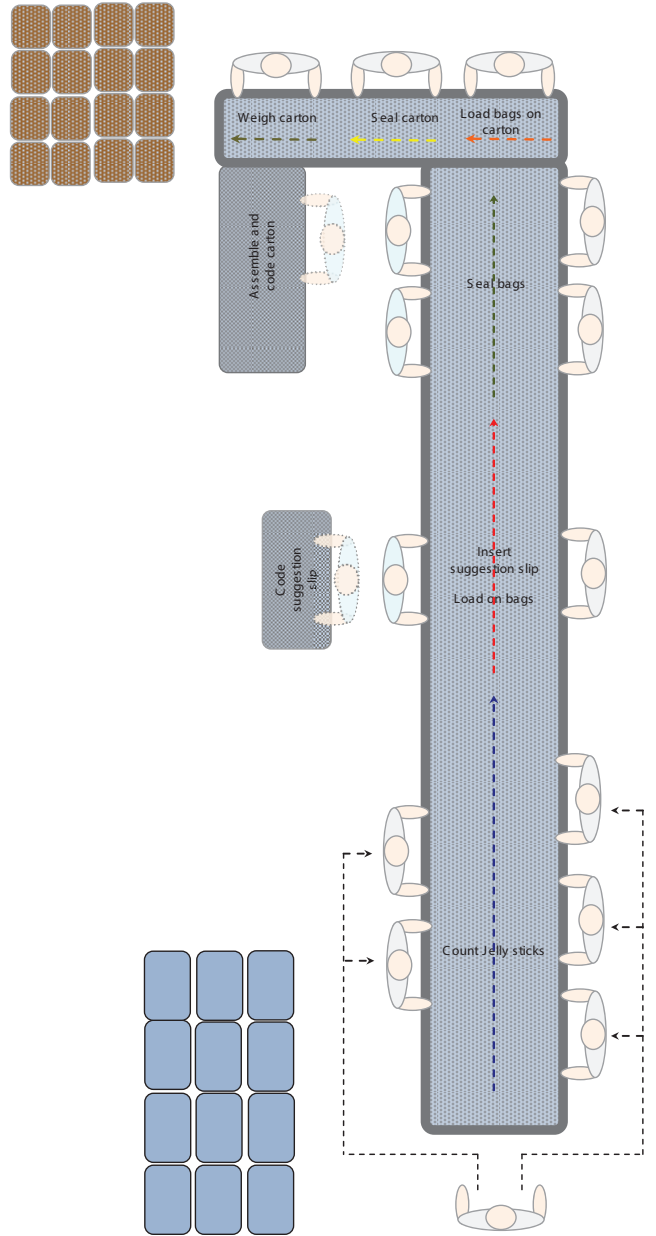

Figure 4 Configuration No. 1 flow diagram. 

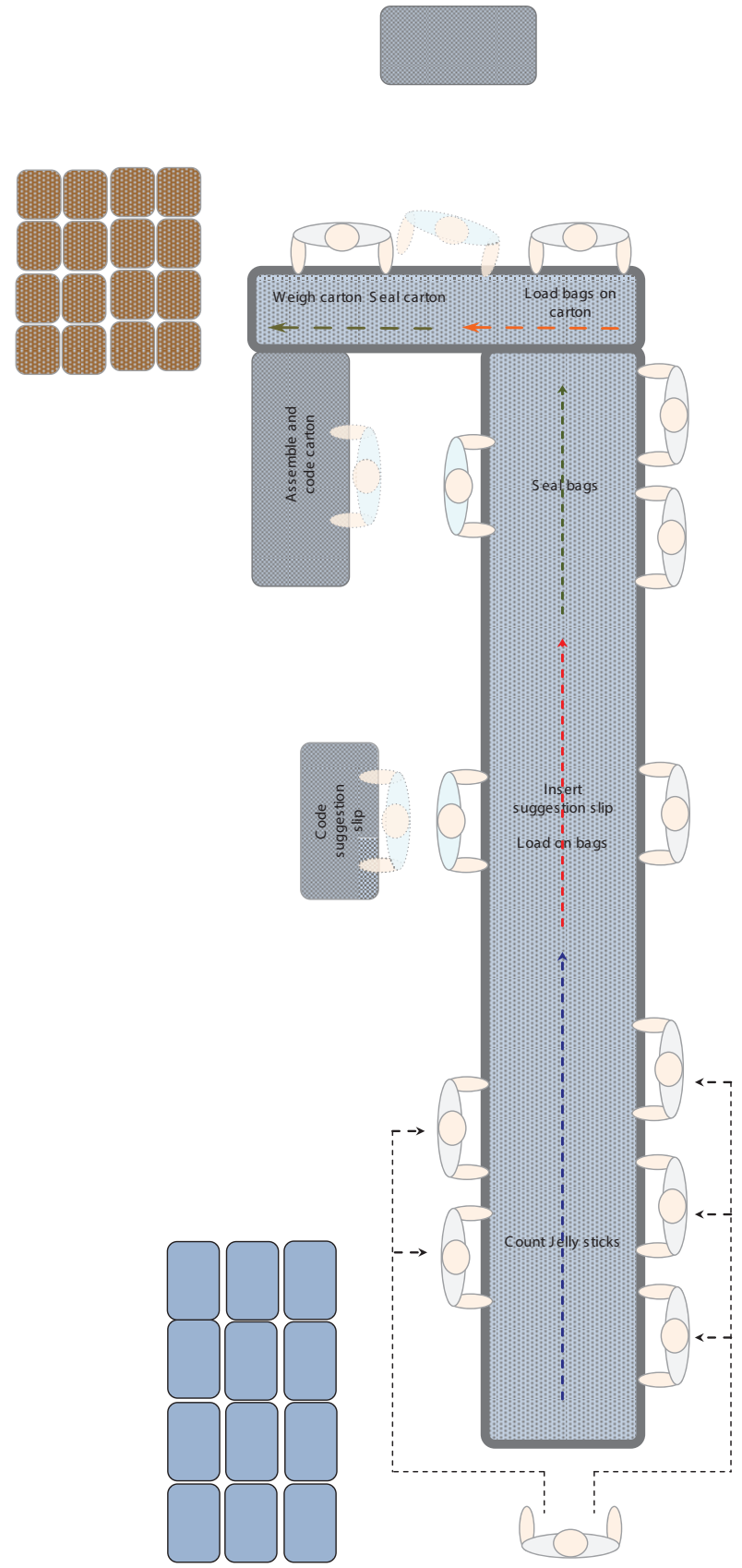

Figure 5 Configuration No. 2 flow diagram. 
Table 5 Configuration No. 2

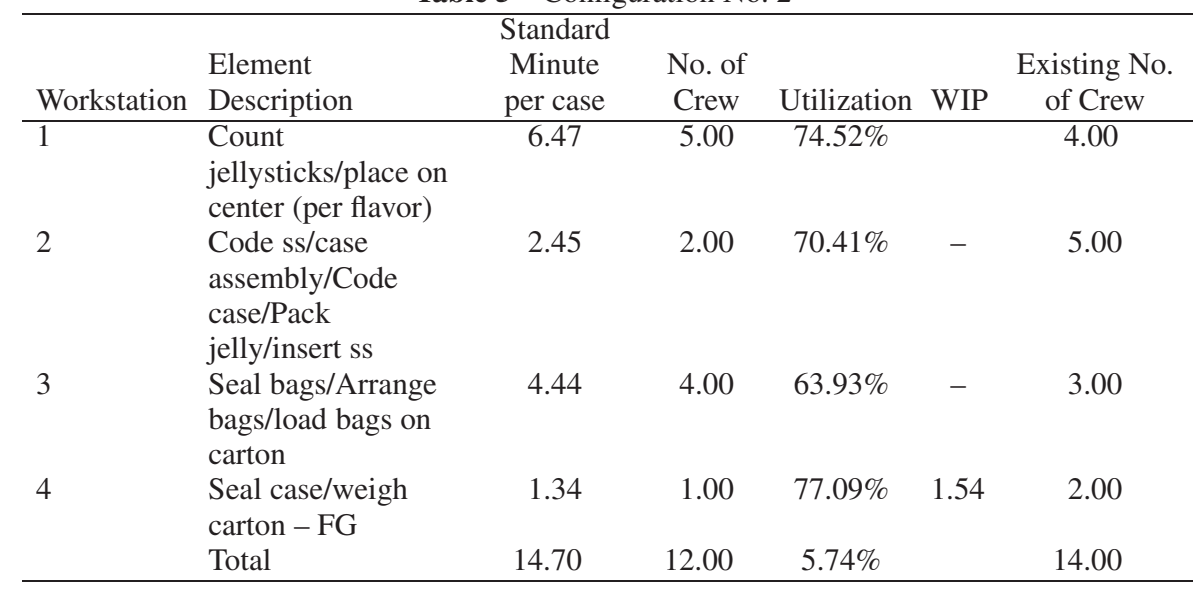

\subsection{Comparative Analysis of Different Configurations}

Given the above discussed configurations, these decision support systems have been evaluated. There are four criteria considered able to measure the effectiveness of each configuration. The following tables show the comparative analysis of these configurations.

Table 6 Configuration No. 1 against existing set-up

\begin{tabular}{|c|c|c|c|}
\hline \multirow[b]{2}{*}{ Workstation } & \multirow[b]{2}{*}{ Element Description } & \multicolumn{2}{|c|}{ No. of Crew } \\
\hline & & Configuration No. 1 & Existing Set-up \\
\hline 1 & $\begin{array}{l}\text { Count jellysticks/place on } \\
\text { center (per flavor) }\end{array}$ & 5 & 4 \\
\hline 2 & Code suggestion slips & 2 & 1 \\
\hline 3 & $\begin{array}{l}\text { Pack jelly sticks on } \\
\text { preformed bag/Insert ss }\end{array}$ & & 2 \\
\hline 4 & Seal bags & 4 & 2 \\
\hline 5 & $\begin{array}{l}\text { Carton assembly and code } \\
\text { carton }\end{array}$ & & 2 \\
\hline 6 & $\begin{array}{l}\text { Arrange bags/load bags on } \\
\text { carton }\end{array}$ & 1 & 1 \\
\hline 7 & Seal carton & 1 & 1 \\
\hline \multirow[t]{3}{*}{8} & Weigh carton - FG & 1 & 1 \\
\hline & Total & 14 & 14 \\
\hline & Considerations & Alternative No. 1 & Existing Setup \\
\hline \multicolumn{2}{|c|}{ Build-up of work-in-process } & None & $\begin{array}{c}5.30 \text { cases } / \mathrm{hr} \text { at } \\
\text { workstation } 4\end{array}$ \\
\hline \multicolumn{2}{|c|}{ Utilization \% (standard deviation) } & $15.31 \%$ & $33.52 \%$ \\
\hline \multicolumn{2}{|c|}{ Capacity of the line (cases/hr) } & 46.36 & 37.08 \\
\hline \multicolumn{2}{|c|}{ Computed labor-hour per case } & 0.2894 & 0.3618 \\
\hline
\end{tabular}


A Decision Support System to Determine the Ideal Number of Workers

Table 7 Configuration No. 2 against existing set-up

\begin{tabular}{|c|c|c|c|}
\hline \multirow[b]{2}{*}{ Workstation } & \multirow[b]{2}{*}{ Element Description } & \multicolumn{2}{|c|}{ No. of Crew } \\
\hline & & Configuration No. 2 & Existing Set-up \\
\hline 1 & $\begin{array}{l}\text { Count jellysticks/place on center } \\
\text { (per flavor) }\end{array}$ & 5 & 4 \\
\hline 2 & Code suggestion slips & & 1 \\
\hline 3 & Carton assembly and code carton & 2 & 2 \\
\hline 4 & $\begin{array}{l}\text { Pack jelly sticks on preformed } \\
\text { bag/Insert ss }\end{array}$ & & 2 \\
\hline 5 & Seal bags & 4 & 2 \\
\hline 6 & $\begin{array}{l}\text { Arrange bags/load bags on } \\
\text { carton }\end{array}$ & & 1 \\
\hline 7 & Seal carton & 1 & 1 \\
\hline \multirow[t]{2}{*}{8} & Weigh carton - FG & & 1 \\
\hline & Total & 12 & 14 \\
\hline & Considerations & Configuration No. 2 & Existing Set-up \\
\hline \multicolumn{2}{|c|}{ Build-up of work-in-process } & $\begin{array}{c}1.54 \text { cases } / \mathrm{hr} \text { at } \\
\text { workstation } 7 \& 8\end{array}$ & $\begin{array}{l}5.30 \text { cases } / \mathrm{hr} \text { at } \\
\text { workstation } 5\end{array}$ \\
\hline \multicolumn{2}{|c|}{ Utilization \% (standard deviation) } & $5.74 \%$ & $33.52 \%$ \\
\hline \multicolumn{2}{|c|}{ Capacity of the line (cases/hr) } & 46.36 & 37.08 \\
\hline \multicolumn{2}{|c|}{ Computed labor-hour per case } & 0.2481 & 0.3618 \\
\hline
\end{tabular}

Table 8 Configuration No. 1 against Configuration No. 2

\begin{tabular}{|c|c|c|c|}
\hline \multirow[b]{2}{*}{ Workstation } & \multirow[b]{2}{*}{ Element Description } & \multicolumn{2}{|c|}{ No. of Crew } \\
\hline & & Configuration No. 1 & Configuration No. 2 \\
\hline 1 & $\begin{array}{l}\text { Count jellysticks/place on center } \\
\text { (per flavor) }\end{array}$ & 5 & 5 \\
\hline 2 & Code suggestion slips & 2 & 2 \\
\hline 3 & $\begin{array}{l}\text { Pack jelly sticks on preformed } \\
\text { bag/Insert ss }\end{array}$ & & \\
\hline 4 & Carton assembly and code carton & 4 & \\
\hline 5 & Seal bags & & 4 \\
\hline 6 & $\begin{array}{l}\text { Arrange bags/load bags on } \\
\text { carton }\end{array}$ & 1 & \\
\hline 7 & Seal carton & 1 & 1 \\
\hline \multirow[t]{3}{*}{8} & Weigh carton - FG & 1 & \\
\hline & Total & 14 & 12 \\
\hline & Considerations & Configuration No. 1 & Configuration No. 2 \\
\hline \multicolumn{2}{|c|}{ Build-up of work-in-process } & None & $\begin{array}{c}1.54 \text { cases } / \mathrm{hr} \text { at } \\
\text { workstation } 7 \& 8\end{array}$ \\
\hline \multicolumn{2}{|c|}{ Utilization \% (standard deviation) } & $15.31 \%$ & $5.74 \%$ \\
\hline \multicolumn{2}{|c|}{ Capacity of the line (cases/hr) } & 46.36 & 46.36 \\
\hline \multicolumn{2}{|c|}{ Computed labor-hour per case } & 0.2894 & 0.2481 \\
\hline
\end{tabular}




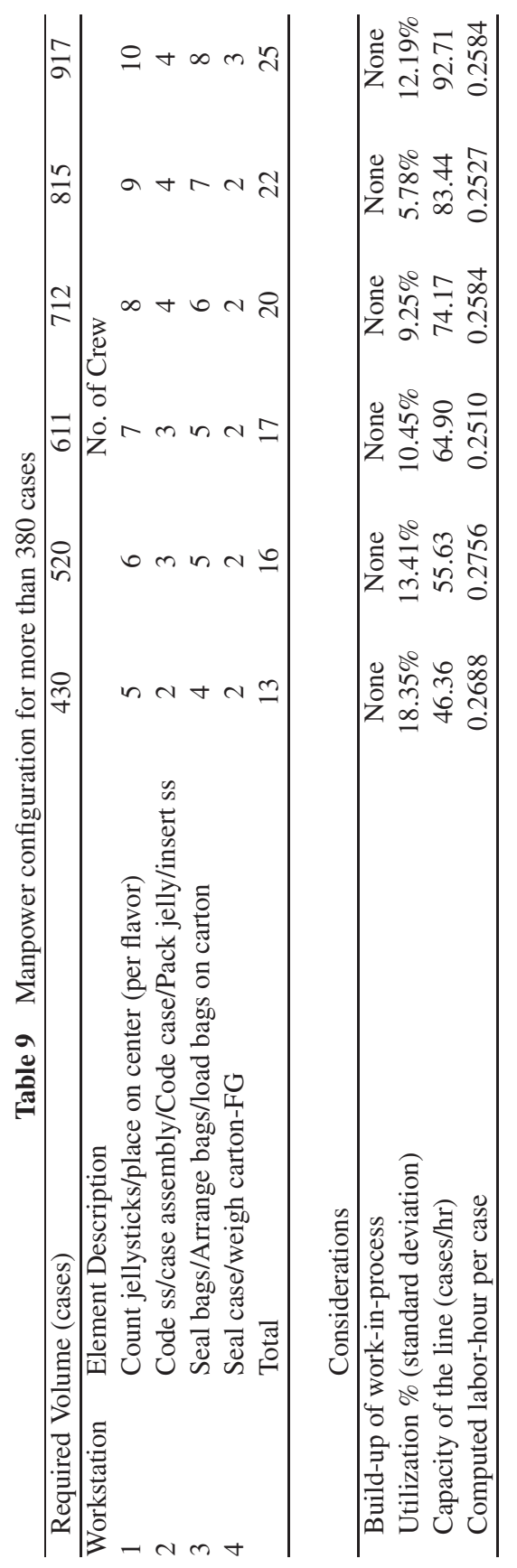


Nevertheless, these configurations will act only as a decision support system that will aid the person in charge in estimating the manpower requirement per workstation. These decision support systems will assist the line leader in analyzing the optimal manpower set-up so as people are effectively and efficiently utilized.

\section{Conclusion and Recommendation}

The study initially seeks to establish standard time for manual packing of jelly products line of a local manufacturing company. Accordingly, line balancing method is utilized to develop a decision support system in determining the ideal number of crew per workstation. Four criteria are set in measuring the effectiveness of different configurations. These are zero build-up of workin-process between workstations, minimum deviation of utilization among workstations, capacity of the line, minimum labor-hour per case.

First, Configuration No. 1 is effective when the line is initially hesitant on abrupt change particularly on decrease in number of manpower population of the line. Reorientation of the existing number of manpower set-up based on their standard time in completing tasks and using of "walking worker" will be significant in utilizing manpower during adjustment period heading for the next configuration.

Second, Configuration No. 2 is highly advantageous since it involves clustering of activities into four workstations and using of "walking worker". Given this scheme, there will be a trim down in manpower requirement thus a potential decrease in labor-hour per unit of product. Also, there will be a smaller deviation of utilization per workstations.

Third, Configuration No. 3 will aid the person in charge in estimating the number of manpower per workstation when the production volume requirement is beyond 380 cases. Clustering of workstations and using of a walking worker in Configuration No. 2 has been used in this recommendation.

Given the above scheme, it has been analyzed that work-in-process between activities could be eliminated, variation of utilization of different workstations could be minimized, capacity of line could be maximized and labor-hour per cases could be controlled.

Furthermore, the outcome of the study could be beneficial in the process of manpower planning, instigating a performance control system and initiating a systematic procedure in establishing time standards for other product lines. 


\section{References}

[1] Andris, F. (2009). Niebel's Methods, Standards and Work Design, 12th Edn. New York, NY: McGraw-Hill.

[2] Jay, H., and Barry, R. (2006). An Introduction to Operations Management, 8th Edn. Singapore: Pearson Education South Asia Pte Ltd.

[3] Cleveland Labor Cost (2014). Available at: http://www.clevelandfed.org/ research/trends/2006/0306/labcosts.pdf [accessed February 3, 2014].

[4] Wang, Q., and others (2006). International Journal of Computer Integrated Manufacturing: Determining Number of Workstations and Operators for a Linear Walking-Walker Assembly Line. Bath: University of Bath.

\section{Biography}

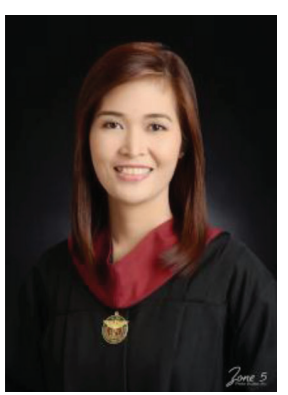

Hazel A. Caparas is a graduate of Master of Science in Industrial Engineering with specialization in Human Factors and Ergonomics at University of the Philippines - Diliman on June 2017. She received Bachelor of Science in Industrial Engineering in Bulacan State University on 2010. She conducted various studies focusing on Process Improvements and Human Factors and Ergonomics. She also acquired solid experience in operations management as an Operations Analyst in a food manufacturing company for four years. Caparas is currently a College Instructor in a State University handling Industrial Engineering courses such as Human Factors and Ergonomics and Facilities Planning and Design. 